\title{
Los "entretantos" del progreso. Representaciones del desarrollo en Brasil y el lugar del Derecho ${ }^{1}$ \\ The "Meanwhiles" of Progress. \\ Brazil's Development Representations and the Place of Law
}

José GaRCez GHirARDi

FGV Direito SP - Brasil

\begin{abstract}
Resumen
La idea del desarrollo como una panacea para los problemas nacionales es recurrente en la política brasileńa, ya que gobiernos ubicados en extremos opuestos del espectro ideológico lo presentan como un paso sine qua non para la búsqueda de la justicia social en el país. El poder judicial brasileño ha desempeñado un papel clave al establecer barreras a lo que las administraciones pueden hacer en nombre de este pretendido ideal. Utilizando la obra $\mathrm{O} B e m$ Amado de Dias Gomes como punto de partida, este trabajo analiza en el Brasil contemporáneo las disputas entre políticos y las cortes.
\end{abstract}

\section{Palabras claves}

Desarrollo / Brasil / Judicatura brasileña / Activismo judicial.

\section{Summary}

The idea of development as a panacea for national problems is recurrent in Brazilian politics, as governments from opposite ends of the ideological spectrum present it as a sine qua non step in the country's quest for social justice. The Brazilian Judiciary has played a key role in establishing barriers to what administrations can do in name of this purported ideal. Using Dias Gomes' play $O$ Bem Amado as a starting point, this paper analyses the clashes between politicians and courts in contemporary Brazil.

\section{Keywords}

Development / Brazil / Brazilian Judiciary / Judicial Activism.

La noción de desarrollo como solución para los problemas nacionales es recurrente en el discurso político brasileño. Gobiernos de diferentes matices ideológicos la utilizan para posibilitar y legitimar sus programas, así como sus modos de gestión.

En especial a partir del proceso de redemocratización de la década de 1980, y de la necesidad de proporcionar justificativos para la elección de modelos específicos, dicha noción es frecuentemente presentada bajo un matiz de neutralidad técnica, que actúa para debilitar el debate sobre valores y elecciones implícitas en modelos diversos, y para descalificar el sentido político de la divergencia. Un corolario de esa perspectiva es la instauración de un proceso de redefinición del papel de las instituciones para que se acomoden a esa misma lógica.

En ese contexto, ha merecido especial atención lo Judicial, visto como elemento crucial para la posibilidad de suceso de modelos específicos de desarrollo. Utilizando la obra teatral, y posterior versión televisiva, de O Bem Amado de Dias Gomes en tanto que alegoría,

\footnotetext{
${ }^{1}$ N. del E.: Este artículo fue originalmente publicado en el año 2012 en el volumen Direito e Economia: 30 anos de Brasil, editado por Maria Lucia Labate Mantovaninni de Padua. La traducción ha estado a cargo de Francisco Venes con correcciones de Diego Falconí Trávez. Se han realizado mínimos cambios al texto y su bibliografía para que se ajustaran a las normas de publicación de la revista.
} 
este artículo analiza brevemente aspectos de la representación de la idea de desarrollo en Brasil, su impacto en el discurso de la política y sus relaciones con los límites impuestos por las instituciones jurídicas.

\section{Las opciones “desafortunadamente" son pocas: desarrollo y elección política}

Los índices de desarrollo son registros de percepciones específicas. Las evaluaciones del grado de desarrollo proponen como premisas, más o menos explícitas, un "antes" y un "después", una "lógica de recorrido" y un "sistema de valoración" de ese recorrido. En su construcción, ellas usan un repertorio conceptual y estratégico que refleja los postulados de la ciencia moderna sobre la cual se fundan, heredando de ella la reivindicación de neutralidad discursiva (Lyotard, 2004). Los índices de desarrollo se presentan entonces como "constatación" o "registro", como dato bruto que precede el análisis e instruye el debate, como elemento que precede y limita decisiones políticas posteriores. La dinámica de su construcción que supone necesariamente recortes, elecciones y valoración (¿qué magnitudes observar? ¿Qué variables incluir? ¿Qué criterios adoptar?) se vuelve con frecuencia invisible, una vez que las apropiaciones de dichos índices y su uso como elemento autorizador de discursos terminan por encubrir la dimensión electiva, política de su configuración inicial.

Ejemplo de ese funcionamiento que oscurece y neutraliza, en el campo práctico, el aspecto construido de las mediciones es el discurso de la política económica que, frecuentemente, hace un recorrido que va de la presentación de un conjunto de datos numéricos (representados como "neutros", "científicos") a justificar la necesidad de implementación de medidas determinadas (comúnmente presentadas como "técnicas" o "apolíticas"). El repertorio de datos analizados y la lógica de su agrupamiento establecen un diagnostico o representación de la "situación concreta" que reduce significativamente el espectro de respuestas políticas efectivamente posibles. Es exactamente lo que afirma John K. Galbraith (1986) en un libro dedicado — dato importante $\complement^{2}$ a la difusión de las matrices que estructuran el debate sobre cuestiones económicas entre el público general:

En nuestras discusiones políticas diarias, creemos muy importante saber si un individuo es de derecha o de izquierda, liberal o conservador, un exponente de la libre iniciativa o del socialismo. No entendemos que, a menudo, las circunstancias sobrevienen y fuerzan a todos a tener una misma actitud —o a todos los que se preocupan por sobrevivir-. Si es necesario acabar con la contaminación del aire para que podamos respirar, o evitar el desempleo o la inflación para demostrar nuestra competencia en la administración económica, entonces no existe una gran diferencia entre lo que conservadores, liberales o socialdemócratas están forzados a hacer. Las opciones, desafortunadamente, son pocas (Galabraith, 1986, p. 1).

El tipo de argumento estipulado por Galbraith acaba por determinar que la posibilidad, esencialmente política, de la elección se vea limitada por el carácter inexorable de la racionalidad técnica que "describe" lo real. Su estructura argumentativa es ejemplar por la forma como conyuga una creencia simultánea en la "neutralidad" de la lectura de los hechos ("contexto"), en la "matriz técnica" de la solución específica ("nuestra competencia en administración

\footnotetext{
${ }^{2}$ Importante porque la naturalización de esa premisa en el público general (el trabajo de Galbraith resultó en una exitosa serie de programas televisivos) tendrá un impacto significativo en el comportamiento de la masa de electores en regímenes democráticos. En el caso específico de A Era da Incerteza es posible sostener que la popularización y reiteración características de los modos de operar de los mass media habrían contribuido de forma decisiva en la consolidación de una creencia en el público inglés: el carácter fundamentalmente técnico de decisiones económicas, tal como está postulado por Galbraith.
} 
económica") y en la "irrelevancia" de las diferencias políticas ("no existe una gran diferencia entre conservadores y liberales”). El silogismo propuesto parece ser:

Si hay un conjunto de circunstancias $(\mathbf{A}), \mathrm{y}$

Si hay un deseo de sobrevivir a (A), (generalmente este es el caso)

Entonces la solución competente en administración económica es (B).

Constatada de modo objetivo una determinada situación, un conjunto de medidas eficaces surgen de ella; y la única decisión que cabrá al cuerpo político será la de tomarlas o no, en un cuadro en el que la elección parece debatirse entre aplicar medidas "adecuadas" o, por ejemplo, tocar un tango argentino. No sorprende, de este modo, que los discursos de política económica se valgan, tantas veces, de metáforas como la del "remedio amargo". En efecto, la voluntad del sujeto es la de rechazar la ingestión del mejunje insoportable, pero la racionalidad técnica del médico lo ayuda a entender que, si el deseo es recuperar la salud, entonces no hay otro camino (p. 2). Galbraith seguramente no supone, como lo hace Molière, que el enfermo pueda ser imaginario, ni como lo hace Machado, que el alienado pueda ser el alienista. La objetividad matemática, de que se nutre ese tipo de apropiación del discurso económico, decreta la impertinencia sustantiva del debate político.

Esa perspectiva genera un reorganización en el campo de los discursos de tal forma que la suposición de una objetividad científica, que deja de lado la voluntad de los sujetos (discurso económico), actúa para descalificar, como retórica vacía, los discursos que tienen por objeto central articular la voluntad de esos mismos sujetos (discurso político). Dicha descalificación de la política puede asumir la forma extrema — aunque, desafortunadamente, corriente — de la dictadura, que destruye libertades individuales y colectivas, como justificación de que estas son contrarias al desarrollo económico que conlleva el bienestar general — supuesto objetivo de la buena política一. Tal como observan Przeworksi y otros ${ }^{3}$ : "hacia 1960, [...] muchos académicos y políticos llegaron a la conclusión de que aquello que se percibía como efectividad económica en las dictaduras era simplemente un hecho de la existencia que debíamos enfrentar con valentía, admitiendo que la democracia era un lujo que sólo podríamos permitirnos después de concretada la dura tarea del desarrollo" $(2000 \text {, p. } 2)^{4}$.No obstante, los regímenes democráticos también manifiestan, a su modo, el impacto de esa retracción de lo político como espacio de múltiples elecciones. Un indicio más familiar de esa anulación práctica de las diferencias puede verse en los expresivos porcentuales con los cuales fueron elegidos y reelegidos (los llamados landslides electorales) aquellos dirigentes que se presentaban como fiadores de una determinada política económica. El Partido Conservador de Margareth Thatcher, por ejemplo, recibió en 1983 cerca de $61 \%$ de los votos, el más grande porcentaje en una elección desde el fin de la Segunda Guerra Mundial. Significativamente, en 2001, sería el Partido Laborista de Tony Blair quien obtuvo el voto de aproximadamente $62 \%$ de los británicos 5 . El movimiento pendular de masiva adhesión popular a partidos representando perspectivas políticas —en teoría sustancialmente diversas - parecería confirmar la previsión de Galbraith sobre la indiferencia práctica del sesgo político que separa conservadores y liberales. En los Estados Unidos, Ronald Reagan, en 1984, obtuvo el margen más grande de la historia del sistema de Colegios Electorales: 525 votos versus

\footnotetext{
${ }^{3}$ N. del E.: Todas las traducciones al inglés fueron realizadas por el autor y luego, a su vez, traducidas al español por el traductor, quien ha dejado las notas originales en inglés en nota al pie.

4 "Around $1960[\ldots]$ many scholars and politicians concluded that the perceived economic effectiveness of dictatorships was simply a fact of life, one that should be confronted courageously by admitting that democracy was a luxury that could be afforded only after the hard task of development had been accomplished".

${ }^{5}$ Para más información sobre las elecciones británicas, véase www.ukpolitical.info.
} 
13 de Walter Mondale (el margen de votación popular también fue indicativo, con Reagan obteniendo casi $60 \%$ de la preferencia, la diferencia más grande desde Nixon, en 1972) ${ }^{6}$. En Brasil, las elecciones de 1994 y 1998 ni siquiera tuvieron segunda vuelta. Fernando Henrique Cardoso derrotó dos veces a Luís Inácio Lula da Silva ( $55 \%$ de los votos válidos versus cerca de $27 \%$ en 1994 , y $53 \%$ versus $32 \%$ en 1998). En un movimiento que recuerda el de las elecciones inglesas, sería Lula quien obtendría después dos victorias por un amplio margen (aunque no en la primera vuelta): $61 \%$ versus 38\% de José Serra en 2002 y $60 \%$ versus 39\% de Geraldo Alckmin, en 2006.

Esa elevada concentración de votos en sociedades de composición bastante plural apunta hacia el surgimiento de una tendencia a la convergencia y al consenso. Y este consenso (político) ha sido construido a partir de un discurso que sugiere que existe, técnicamente, una alternativa más adecuada para la consecución de determinados fines - lo que, en términos prácticos, significa decir que apenas hay "una" alternativa deseable-. "It's the economy, stupid": la famosa frase de campaña de Clinton, en la que venció a George Bush, sintetiza bien la relación de los campos discursivos. Solamente un idiota podría centrar el debate en cuestiones de matrices políticas si, de hecho, lo que interesa a las personas es el bienestar cotidiano, entendido como consecuencia directa del desarrollo económico8.

Es el consenso (real o supuesto) sobre el valor de un determinado modelo de desarrollo conducente a ese bienestar el que hace posible que grupos sociales con intereses diversos converjan masivamente hacia una solución única. Ese consenso es, también, el que vuelve políticamente posible solicitar el sacrificio presente (desigual) de las voluntades individuales y colectivas en favor de un bien mayor futuro. Nuevamente, las metáforas iluminan la lógica casi religiosa de adherencia a un determinando proyecto de desarrollo: "contribuir con su cuota de sacrificio", "apretar el cinturón", "cumplir con su parte". La premisa parece ser que el desarrollo, construido como consecuencia de la implementación responsable de medidas económicas eficaces resultará, en última instancia, en un beneficio para todos los sectores de la sociedad y elevará el nivel de bienestar general. En esos términos, adherirse a él se impone casi como un producto lógico, en una dinámica que remite a la observación de Habermas de que "la movilización del consentimiento produce el poder, que a través de la utilización de los recursos sociales se transforma en decisiones obligatorias" (Habermas, 2001, p. 102). Esto, cabe añadir, no sólo ocurre en el ámbito de los países considerados individualmente. En el escenario internacional, se observó el apogeo de esta curiosa armonía respecto al carácter deseable de determinadas medidas económicas en un evento que quedará conocido como el Consenso de Washington .

De ahí resultan por lo menos dos consecuencias. La primera radica, justamente, en instalarse en una creencia de que es posible avanzar por consensos, una vez que las divergencias

\footnotetext{
${ }^{6}$ Para más información sobre las elecciones estadounidenses, véase www.uselectionatlas.org.

${ }^{7}$ Para más información sobre las elecciones brasileñas, véase www.tse.gov.br.

${ }^{8}$ Ver la discusión que Manuel Castels (1999, pp. 176-189) hace del neoliberalismo y del problema de la pensée unique conforme postulada por Ramonet.

${ }^{9}$ Bresser Pereira define al Consenso de Washington como "the neoliberal approach that, having Washington as geographical origin, has a powerful influence over governments and elites in Latin America. According to this approach, the causes for the Latin American economic crisis are basically two: (1) excessive state intervention, expressed in protectionism, over-regulation and an oversized public sector and (2) economic populism, depicted as fiscal laxity, the unwillingness to eliminate the budget deficit. Following this assessment, economic reforms should in the short run combat economic populism and control the budget deficit, while in the medium run they should embrace a 'market-oriented' strategy of growth, i.e., reduce state intervention, liberalize trade and promote exports" (1991, p. 3).
} 
pueden ser arbitradas por referencia a patrones objetivos de medición. La segunda, corolario de la anterior, es que la divergencia en cuanto a medios y fines es menos un acto de "elección política" y más un "producto"; sea por la incapacidad para la comprensión de la realidad (los adversarios políticos son "primarios", "retrógrados", "ignorantes") o sea por la mala voluntad hacia el colectivo (los adversarios políticos son "reaccionarios", "burgueses", "elitistas"). El debate político se descalifica en este proceso como espacio de divergencias. Así, bajo el "valor" del desarrollo el debate político se ve reducido, por un lado, a una incompetencia técnica y, por otro, a una torpeza moral ${ }^{10}$.

Ambas consecuencias resultan, como se mencionó, de la naturalización del "valor" de un modelo, de su carácter apriorísticamente deseable y no problemático, de la percepción de su superioridad como un "hecho". Es esta percepción que parece estar en el centro del diagnóstico del "fin de la historia", propuesto por Fukuyama, que resultaría del "agotamiento completo de las alternativas sistemáticas y factibles, al liberalismo occidental” (1998, p. 114) ${ }^{11}$. No el fin de toda la historia, nótese, pero el fin de la historia como un choque entre alternativas ideológicas concurrentes, el fin de la historia de sujetos que divergen en sus "elecciones básicas" de manera fundamental e irreconciliable - y que divergen por razones cuya validez no puede ser arbitrada objetivamente, una vez que es declaradamente ideológica.

Ese proceso de "naturalización" de determinadas perspectivas de desarrollo, y la instauración de una tendencia a un tipo de "consenso" que descalifica diferencias —al negarles el reconocimiento de la dimensión política - tuvo, en Brasil, características peculiares que deben mencionarse. La larga tradición patrimonialista brasileña se conjugó como un modelo específico de desarrollo con un sistema cuyas múltiples paradojas han sido tema central de influyentes reflexiones sobre el país ${ }^{12}$. Dichas paradojas, profundas y llenas de consecuencias —como de hecho lo son- se abrazan en el campo de los discursos, con una naturalidad que no permite diferenciarlas. Y se entrelazan justamente a partir del consenso de que la realidad insoportable de la miseria sólo puede superarse por la naturaleza redentora del desarrollo. La pluralidad de presentaciones a las que se presta el carácter amplio y con múltiples formas del término no permite apenas exhibir unidad en la contradicción y acomodar opuestos inconciliables, pero le asegura permanencia y recurrencia sin paragón, como mantra sanador de los males brasileños.

Apropiado y resignificado, sin solución de continuidad, por diferentes gobiernos y diferentes líneas políticas (de la "Orden y Progreso" de la Primera República, pasando por Getúlio, Juscelino, la dictadura militar, hasta llegar a Collor, Itamar, FHC, y Lula) ${ }^{13}$, este axioma del desarrollo —en un esquema fundamentalmente binario que opone pobreza/desarrollo, injusticia/justicia, atraso/modernidad - se ha perpetuado con una naturalidad que escamotea la lógica con la cual se componen sus contradicciones. Es en torno de ese concepto clave - y de sus múltiples y antitéticos significados- que se crean políticas y se autorizan instituciones. Esta

\footnotetext{
${ }^{10}$ Esa "descalificación de lo político" podría ayudar a entender dos problemas contemporáneos: la reducción gradual de la importancia de lo Legislativo como fuente de propuestas políticas sustantivas (una vez que ella exigen un patrón de "calidad técnica" y celeridad que los grandes cuerpos colegiados tienen dificultad para alcanzar) y la percibida reducción del interés popular por el debate político (una vez que bajo esta perspectiva no hay, de hecho, una "elección" entre alternativas diversas sino simplemente la decisión acerca de la forma y el momento para implementar una perspectiva técnica cuya complejidad escapa al ciudadano común).

11 "[T] he total exhaustion of viable systematic alternatives to Western liberalism".

${ }^{12}$ Las contradicciones del proceso de formación del país han sido constantes en nuestro debate académico. En las reflexiones sobre sus matrices económicas, los clásicos estudios de Caio Prado Jr. (2011) y de Celso Furtado (2007) permanecen como ejemplos magistrales por su agudeza y elegancia.

${ }^{13}$ N. del T.: Los nombres mencionados por el autor son de ex presidentes de la República Federativa de Brasil. FHC son las iniciales de Fernando Henrique Cardoso.
} 
construcción del desarrollo como meta colectiva, ya se mencionó, frecuentemente se articula por medio de la descalificación impaciente de la divergencia política, creando una tensión que a veces osa pasar los límites de la organización democrática. El modo a través del cual dicho proceso se desarrolla en Brasil, y el rol que en el ejercen las instituciones (sobre todo las jurídicas), serán discutidos en las siguientes secciones y tendrán como hilo conductor el análisis de $O$ Bem Amado de Dias Gomes.

\section{2. "Vote por un hombre serio y gane su cementerio": Odorico, patrimonialismo y desarrollo}

O Bem Amado ${ }^{14}$ de Dias Gomes, es uno de esos rarísimos textos que se vuelven iconos de la cultura brasileña por la simplicidad con que, en su tiempo, descifran y problematizan la lógica que subterráneamente rige la vida en el país. El pastiche creado por Dias Gomes en torno del discurso desarrollista del personaje central, Odorico Paraguaçu, de las resonancias sociales que genera y del resultado final que obtiene, sintetiza, sin querer ser reduccionistas, el conjunto de problemas mencionados anteriormente.

Odorico es, antes de todo, un coronel —en el sentido peyorativo que Dias Gomes deja antever en la pieza-. Su lógica es la del despótico latifundista cuyo poder y prestigio social se apoya, en última instancia, en la miseria crónica de Sucupira. El descompás entre sus intereses y los del pueblo en general es, desde luego, evidente, lo cual vuelve cómica la pretensión de hacerse representante justamente de los destituidos que explota. El nudo de la historia se compone a partir de la legitimación política que obtiene y en función de la elección de un objetivo que, haciendo caso omiso a las necesidades de la vida presente (se trata, a fin de cuentas, y como explicaré ahora, de un cementerio), postula una inusitada convergencia de intereses futuros. Y el nudo se enrolla aún más porque Odorico construye su discurso electoral postulando que los males de Sucupira, ciudad en todo bendecida por la naturaleza, ocurren por los desaciertos de un gobierno que sólo cuida de los intereses foráneos, en detrimento de las necesidades de la población local. La cita es por demás divertida:

ODORICO: Lo dice muy bien Doña Dorotéa Cajazeira, comprometida profesora de nuestra escuela. Es increíble que esta ciudad, orgullo de nuestro estado por la belleza de su paisaje, por su clima privilegiado, por su agua radioactiva, por su aceite de dendé, que es mejor del mundo, hasta hoy no tenga aún dónde enterrar sus muertos. Ese alcalde que ahí está...

DOROTÉA, DULCINÉA Y JUJU: (abuchean) ¡Buuuuu!

ODORICO: Ese alcalde que ahí está, ¿qué ha hecho hasta ahora para satisfacer el más grande anhelo del pueblo de esta tierra?

DIRCEU: ¡Sólo piensa en construir hoteles para veraneantes!

DULCINÉA: ¡Embotellar agua para vender a los veraneantes!

ODORICO: Todo para veraneantes, personas que vienen acá pasar uno o dos meses y regresan sus tierras, donde, seguramente, no falta un cementerio. ¡Pero aquí también habrá! ¡Aquí también habrá un cementerio!

JUJU: (Grita histéricamente) ¡Queremos nuestro cementerio!

DOROTÉA, JUJU, DIRCEU E DULCINÉA: ¡Queremos nuestro cementerio! ¡Queremos nuestro cementerio!

ODORICO: Y lo tendremos. ¡Ciudadanos sucupiranos! Si salgo elegido en las próximas elecciones, mi primer acto como alcalde será ordenar la construcción inmediata del cementerio municipal.

TODOS: (Aplausos) ¡Muy bien! ¡Muy bien!

(Una banda surge en medio de la gente)

\footnotetext{
${ }^{14}$ Me refiero, aquí, a la pieza de teatro escrita en 1962. Pero creo que, como yo, muchos se acuerdan con nostalgia de su versión televisiva (1973).
} 
Los "entretantos" del progreso. Representaciones del desarrollo en Brasil y el lugar del Derecho

\section{VOTE POR UN HOMBRE SERIO Y GANE SU CEMENTERIO}

ODORICO: Un buen gobernante, mi gente, es aquel que gobierna con el pie en el presente y el ojo en el futuro. Y el futuro de todos nosotros es el camposanto (Dias, 2010, pp. 34-35).

La retórica de explotación externa, del atraso local y del desarrollo como panacea, que está presente en el discurso de Odorico es cómica no sólo por lo inusitado de su objeto, sino también porque reproduce "temas" fundamentales del discurso político brasileño ${ }^{15}$. El binarismo que el discurso articula y el carácter único de la solución que este proyecta operan inmediatamente para crear la sensación de "no-elección" a la cual se refería Galbraith. A fin de cuentas, quien es "serio", querrá, forzosamente, su "cementerio". Además, permite volver impertinentes demandas populares plausiblemente más inmediatas (agua, escuela, sueldos), ya que dificultan la obtención del desarrollo en los moldes que da el coronel.

Este despropósito que inicia la trama de $O$ Bem Amado esconde, en el énfasis que da el poder de facto del coronel y el evidente atrevimiento con el que lo ejerce, un hecho que tendrá más adelante una importancia crucial. Odorico es elegido. Aunque poderoso, él necesita para implementar su proyecto del "aparato institucional" representado por el cargo de alcalde, al cual sólo es posible acceder por medio de una elección. Que su victoria en las urnas tenga por base una propuesta sin sentido y el cebo de un pueblo crédulo y sufrido, que se deja fascinar por las ventajas imaginadas del camposanto, no invalida la constatación de que hasta el mismo poder del coronel debe adecuarse a requerimientos de otro orden. Esa validación complica el escenario, al volver menos distintos los términos que lo componen. La yuxtaposición momentánea de dos campos de poder —económico/político y de facto/de derecho- crea la ilusión de que no hay entre ellos una diferencia real y de que las instituciones son apenas un instrumento dócil en el proceso de perpetuación de los titulares del poder (de hecho/de derecho).

De entre las muchas impropiedades que podrían resultar del triunfo electoral de Odorico y de su celebración como "buen gobernante" valdría destacar — como ilustración elocuente de la lectura que Roberto Schwarz hace de la comedia intelectual brasileńa (1992) _ que es el coronel retrógrado quien surge como paladino del progreso y de la modernización, y el latifundista rico quien surge como legítimo promotor de los intereses destituidos. Lo que hace posible la paradoja es la forma de representación política que el discurso del desarrollo establece: se cree que el valor del modelo propuesto no depende de la condición de los sujetos afectados por él. La creencia de que la falta de un cementerio es una vergüenza general, colectiva - y que, por lo tanto, iguala a ricos, pobres y clase media - vuelve impertinentes las consideraciones sobre las desigualdades entre los grupos sociales. El debate sobre el grado en el cual cada individuo disfrutará efectivamente de la bonanza futura debe quedar en suspenso, en una lógica que remite a la idea de hacer crecer el pastel para después repartirlo. Las demandas individuales previas a ese desenlace futuro no son apenas intempestivas — son políticamente inaceptables-, una vez que esa representación del desarrollo activa el axioma corriente de que el colectivo debe prevalecer sobre lo individual.

De esa manera, aquellos que cuestionan ese proyecto de desarrollo y que, en el transcurrir del enredo, lucharán por el respeto de la ley y de las instituciones, reciben el

\footnotetext{
${ }^{15} \mathrm{El}$ tema parece ser casi obligatorio, por ejemplo, en los discursos de posesión de la Presidencia de la República: "Así yo vi mis hijos nacer, mis nietos, soñando y luchando por divisar el día en que el desarrollo, la libertad y las justicia - justicia, libertad y desarrollo - caminarían juntos en esta tierra" (Cardozo, 1995). Y por parte de Lula: "carecemos de un auténtico pacto social por el cambio y una alianza que entrame objetivamente el trabajo y el capital productivo, generadores de la riqueza fundamental de la Nación, para que el Brasil supere la estagnación actual y para que el País vuelva a navegar el mar abierto del desarrollo económico y social (Da Silva, 2008, p. 11).
} 
apodo de retrógrados o de enemigos resentidos de la felicidad general de la nación ("Yo sé que hay mucha gente que no respeta a los muertos, ni cree en Dios. No es para esos ateístas impenitentes que construiremos nuestro cementerio" [Dias, 2010, p. 38]). Actuando a partir de su mal disfrazado interés personal (el suceso del proyecto será la apoteosis del poder del coronel), Odorico descalifica las voces contrarias clamando, entre cínico y paradójico, en defensa de los intereses del pueblo en general. Cualquier sugerencia de que ese mismo pueblo pueda salir sustancialmente perjudicado por el modelo adoptado es condenada como mezquina y perniciosa para el cuerpo político:

ODORICO: Necesitamos inaugurar el cementerio, lo más pronto posible. No podemos esperar más.

MOLEZA: Está muy difícil, Coronel. Hay una gran escasez de difuntos. La solución pasa por tener paciencia y fe en Dios.

ODORICO: Para usted es muy fácil tener paciencia. Hace un año que gana como sepulturero sin trabajar.

MOLEZA: Pero no recibo...

ODORICO: Reciba o no, usted es un parasito del municipio. Si fuera un funcionario de buen carácter y amor propio, ya hubiera buscado solucionar esa situación y volverse un ciudadano útil a la comunidad. El señor es una vergüenza y un mal ejemplo para el funcionalismo municipal. ¿ ‘engo o no razón, Dońa Dorotea?

DOROTÉA: Toda. El ciudadano sepulturero es, inclusive, un peligro para la comunidad.

MOLEZA: Peligro, :yo?

DOROTÉA: Peligro por su inactividad, que además de inmoral es un motivo más para que nuestros enemigos nos ataquen.

MOLEZA: Pero, ¿qué culpa tengo yo, si no me dan trabajo?

DOROTÉA: Pero si usted hubiese investigado los antecedentes del ciudadano sepulturero, antes de nombrarlo, hubiera encontrado que él nunca fue de hacer esfuerzos. Hubiese visto el apellido que le pusieron: Moleza ${ }^{16}$.

ODORICO: A ver, yo pretendí, con ese nombramiento, premiarlo por su trabajo en mi campaña. Esperaba que eso fuera también un estímulo para que él se comprometiera a ir en contra de su apellido. Pero de nada sirvió. Es un caso perdido (Dias, 2010, pp. 67-68).

Los reclamos de Chico Moleza, aunque fundamentados en la experiencia concreta de la falta de salarios que el proyecto de Odorico conlleva (la construcción del camposanto acabó con las finanzas del municipio), son descartados como indicadores de su indolencia crónica y de su mal carácter ("vergüenza", "mal ejemplo", "parásito"), lo cual lo vuelve un "peligro" para la "comunidad". En un movimiento central para la comicidad de la pieza, el hambre se vuelve culpa del hambriento pues este es incapaz de contribuir al proyecto de desarrollo colectivo (si Chico Moleza tuviera buen carácter, "ya hubiese procurado solucionar esa situación y volverse un ciudadano útil a la comunidad"). Agotados los recursos de la lógica patrimonialista ("pretendí, con ese nombramiento, premiarlo por su trabajo en mi campaña"), emerge con claridad el carácter problemático del modelo moderno de desarrollo y su promesa de bienestar, frente a las contradicciones internas que la representación colectiva oculta.

No obstante, la creencia en el mantra del desarrollo es resistente y, aún en este momento de la comedia, no es el modelo el que se ve cuestionado, sino las personas que a nombre personal lo implementaron ("nunca fue de hacer esfuerzo [...] es un caso perdido"). En la visión del coronel, el problema reside en el exasperante atraso local, no en el modelo que él presenta para su superación.

\footnotetext{
${ }^{16}$ N. del T.: "Moleza" se traduce al español como "pereza".
} 
Odorico sintetiza de esa manera una de las contradicciones centrales de la experiencia brasileńa. Él se vuelve el (autonombrado) paladín del desarrollo (al cual se vinculan promesas de progreso, de incremento cualitativo de las condiciones de vida, de bienes y modos de consumo, etc.) sin repudiar y antes reforzando la estructura de la cual deviene su poder; estructura que rechaza las premisas sobre las cuales este mismo modelo está asentado en lo teórico (el respeto por las leyes, los derechos individuales y colectivos, la consistencia de las instituciones, etc). De ese desencuentro resulta una consecuencia curiosa pero llena de significado para nuestro argumento: aunque las condiciones concretas de vida se deterioren (la lógica patrimonialista, a nombre del desarrollo colectivo, agota los recursos destinados a las demandas cotidianas de escuelas, abastecimiento, salarios, como ya se mencionó anteriormente), el mito del progreso no pierde su fuerza. Y esta permanencia apunta, una vez más, al papel crucial que las representaciones del desarrollo tienen en la consolidación, al interior del cuerpo político, de aquella pensée unique a la cual ya se hizo referencia.

Un indicador importante de ese desfase entre la representación discursiva del desarrollo y la realidad de la práctica cotidiana es el asombro obsesivo de Odorico por la terminología difícil y grandilocuente, aspecto espectacular del ingenio humorístico de Dias Gomes ("estado de 'difuntez' compulsoria”; "recibir la confirmación, ratificación, la autenticación y, por qué no decir, la consagración del pueblo que me eligió"; "Quiero ver ahora que dirán los que me acusaban de 'demagogista”" [pp. 35, 46, 55]). La cuestionable incorrección vernacular de Odorico no lo desacredita. Una vez que se da la aceptación colectiva de la relevancia de su discurso externo, extraño a la dinámica local, se le confiere prestigio a la oratoria del alcalde y se refuerza su autoridad, aunque (y quizás por eso) el sentido de su enunciación no sea plenamente comprendido. Esta incomprensión es percibida como prueba de que hay un desfase entre atraso (oyente) y modernidad (alcalde) que es necesario superar.

En la paradoja de los discursos vacíos (pero eficaces) con la que Odorico nos hace reír, se representa una acumulación improbable de poder: el prestigio social del antiguo orden patrimonial se ve reforzado, incluso reactualizado, por su asociación con los herméticos modos de enunciar la modernidad. En la superficie, no existe superación, conflicto, ni contradicción, sino la convergencia y reiteración de lugares conocidos, lo que hace posible soñar con la utopía de un progreso que, sin ruptura ni sacudidas, nos lleve, a todos juntos, de la miseria a la abundancia. Las divergencias, las oposiciones y el cuestionamiento de la validez del modelo de desarrollo propuesto son presentados como mala voluntad programática o disparate ideológico. Neco Pedreira, editor del periódico de oposición es un "canalla" de "mal carácter", cuyas críticas Odorico descalifica como "un movimiento subversivo que pretende intrigar la opinión pública y crear problemas a mi administración” (p. 40).

Odorico no desea el progreso, entendido como la ampliación de oportunidades para diferentes sujetos, sino como un instrumento para reforzar y actualizar su posición de mando. La mejoría de la vida colectiva, beneficio subentendido en el discurso del desarrollo, le es absolutamente indiferente -incluso le molesta, dado su interés en mantener el status quo-, siendo prueba innegable de su negligencia su estrategia de repatriar (con dinero público) a la impávida Sucupira, al célebre asesino Zeca Diabo. Le resultará contraproducente, como ya lo veremos, pero no desdice la decisión de sacrificar el colectivo en nombre de lo individual.

El regocijo del coronel con la amenazadora y peligrosa llegada de un asesino sólo resulta paradójica en la superficie pues el fortalecimiento de la miseria (las muertes esperadas) dará sentido al proyecto de desarrollo que él preconiza (el cementerio), reforzando así su poder. De ahí también su desesperación al ver que en la historia el pistolero corra el riesgo de transformarse y abandone la violencia como forma de vida. Este cambio de actitud, aunque plausiblemente representa un beneficio para el conjunto, se ve como algo negativo por parte de Odorico, ya 
que se arriesga a presentar un cambio en las condiciones de vida, lo cual frustraría y dejaría sin sentido el proyecto de desarrollo del que depende su apoyo político. Odorico tiene soluciones para las cuales es urgente encontrar problemas y esto es exactamente lo que el progreso social amenaza robarle.

Como toda caricatura, el humor de Dias Gomes exagera y sobredimensiona ciertos rasgos - y es justamente por eso que se vuelve elemento privilegiado para ayudarnos a comprender el mundo real—. La ampliación cómica sólo puede surtir efecto si mantiene una fidelidad fundamental con las formas que satiriza para, a partir de ahí, explorar sus contradicciones. El microcosmos de Sucupira y la forma primaria con que Odorico disfraza su interés particular, en un proyecto vendido como colectivo, hacen reír porque permiten reconocer, a su manera, dinámicas recurrentes en la experiencia de los discursos sobre desarrollo en el país. Permiten reconocer, también, la compleja importancia de elementos aparentemente secundarios para la narrativa, pero que serán esenciales para el desenlace de la trama: la ley y las instituciones judiciales.

\section{3. "No necesito un doctor en leyes, sino un hombre de acción": Derecho, instituciones, desarrollo}

Elemento crucial para determinar el destino de Odorico Paraguaçu es el papel desempeñado por las instituciones, en general, y por el poder judicial, en particular. El ascenso y descenso del coronel - del refuerzo que su poder recibe, en virtud del proceso electoral, al inesperado límite que le impone el orden judicial— se dan en el marco de su relación con las instituciones y el papel ambiguo que ellas ejercen.

Los primeros movimientos de $O$ Bem Amado escenifican, sin sobresaltos, aquella conversación del "patrimonialismo estatal" al que se refiere Faoro (2001, pp. 819-838). Odorico traduce en legitimación electoral su poder de facto; en servicio público el vasallaje social; y en metas de gobierno la ambición personal. Huelga decir que ese movimiento de privatización personalista de la esfera pública no escandaliza a nadie, pero recibe apoyo del cuerpo social que reconoce en él su forma habitual de organización. Reconocimiento que no excluye y, por lo contrario, refuerza la relevancia del marco institucional dentro del cual se desarrolla. La pantomima del coronel demócrata (como ejemplo de antinomia trágicamente palpable durante el régimen militar) sólo se vuelve "cómica" porque se reconoce, tácitamente, una aceptación de la diferencia insuperable entre los dos términos. Odorico no es risible porque lleve la batuta sino porque desea hacerlo a través de instituciones democráticas. Este reconocimiento del valor específico de las instituciones, aunque ligero y discreto, será decisivo en la pugna de intereses que definirá toda la acción en la trama.

La naturalidad en la conformación del aparato de Estado que sigue la elección (Dirceu Borboleta se vuelve secretario del alcalde; Chico Moleza, en cambio, sepulturero) así como la cooptación de elites y de capas populares refuerzan la noción de que las fronteras entre lo público y lo privado son impunemente permeables, y que no hay límites efectivos para el poder del coronel, que se extiende; vasto como su latifundio. La relación ilícita de Odorico con Dorotéa Cazajeira ilustra ese cuadro más amplio del engańo, mientras que la impavidez de un marido tonto refleja la ingenuidad e inercia de una población que perezosamente se deja timar. La fuerza política que el alcalde capta queda, momentáneamente, en un segundo plano pues, como se mencionó, el funcionamiento sordo de las instituciones que, sin embargo, no están ausentes, se hará escuchar cuando la "situación realmente embarazosa" de escasez de difuntos empiece a desmoronar el consenso levantado a partir de la emoción que generó el proyecto del cementerio. 
De hecho, el derrocamiento de Odorico se inicia justamente cuando queda claro lo absurdo de su proyecto desarrollista. El hiato entre su propuesta y las condiciones locales es de tal envergadura que subvierte el letargo tradicional y posibilita el hecho político: el pedido de impeachment. Pasado un año, ya no es posible vender un proyecto de ambición personal como interés colectivo y los hilos de poder de Odorico se irán rompiendo gradualmente. Es crucial observar, mientras tanto, que aunque esa caída tenga su inicio en la instabilidad causada por el juego político, sólo podrá volverse irreversible por la fuerza de las instituciones (un orden judicial) que, aparentemente cooptadas por el discurso único del poder, surgirán, en ese momento, como elemento de resistencia y preservación de la diferencia.

Una contradicción apenas aparente ocurrirá cuando se active el aparato institucional que tiene su origen en el interior del poder y que opera al revés de sus expectativas. Es Odorico quien nombrará a Zeca Diabo como comisario, reproduciendo la lógica de anulación de las fronteras publico/privado, hace poco mencionada. Mientras tanto Zeca va a rehacer esas fronteras por una insistencia (ingenua) en la importancia de la ley. Esta simpleza reside, justamente, en atribuir valor efectivo a la regulación normativa que la práctica general parece desautorizar. Odorico nombra a Zeca Diabo comisario, con la manifiesta intención de utilizar el aparato público para una venganza privada. Entretanto, en el proceso de reconocer la importancia del "puesto" (y de la lógica de institucionalización del poder que este implica), el coronel deberá admitir tácitamente el límite a su poder:

ODORICO: Muy bien. De hoy en adelante, Capitán Zeca Diabo, usted será mi comisario. ZECA: ¿Comisario? ¿Comisario de policía?

ODORICO: Con carta blanca para agitar el tolete.

ZECA: ¿Y tendré que vestirme de "chapa"17?

MESTRE AMBRÓSIO: No, hombre, el comisario no usa traje.

ZECA: Ah, bueno, si no tengo que vestir el traje de "mono", su merced cuente conmigo.

ODORICO: Hablaré con el gobernador para hacer dimitir al actual comisario, que es un inútil, no captura a nadie, y usted asume su puesto.

MESTRO AMBRÓSIO: ¿Capturar a quién? Esta es una tierra que no produce ladrones.

ODORICO: Produce cosas peores (agarra un periódico). ¿¿Usted sabe leer?

ZECA: De seguido no, pero deletreando sí.

ODORICO: Pues yo quiero que después usted lea esta gaceta deletreando de principio a fin.

Neco Pedreira, ¿ Usted lo conoce?

ZECA: No señor, no lo conozco.

ODORICO: Es el dueño del periódico. Un elemento peligroso. Su primera misión como comisario es allanar la redacción de esa gaceta subversiva y sacudir el tolete en nombre de la ley y de la democracia (Dias, 2010, pp. 77-78).

Es necesario que Zeca Diabo sea comisario para "agitar el tolete" porque este acto de violencia ocurrirá, nominalmente, "en nombre de la ley y de la democracia". Confiado en su poder fáctico y en la obediencia absoluta a la cual se acostumbran los que siempre mandan, Odorico resta importancia al reconocimiento de la primacía de las leyes. Aquí encontrará la raíz de su destrucción pues él cree estar en poder de "dar carta blanca" a Zeca Diabo pero, como ambos descubrirán muy pronto, esta es una creencia equivocada. Al comprender la ley, Zeca entiende la existencia de un funcionamiento institucional como contrapunto al poder de facto, algo que las costumbres sociales ocultaban. La referencia a una autorización más allá del gobernante anuncia el funcionamiento de un engranaje más amplio que Odorico intentará en vano controlar:

\footnotetext{
${ }^{17}$ N. del T.: En el texto original aparece la expresión "macaco" que significa "mono". Opté por traducir "macaco" a "chapa" por tratarse de una referencia peyorativa a la Policía.
} 
ZECA: Doctor, como comisario yo tengo que ser justo. Fui allí con ganas de hacer que el chico tragase todo lo que dijo. Pero él hizo que nos sentemos y conversemos. Me mostró la ley que le garantiza decir lo que él quiera. Una ley hecha por los diputados, no sé si su merced conoce... (p. 78).

Zeca disocia las voluntades que Odorico reuniera y empieza a deshilar el nudo público/privado que la elección trenzó. Su "ansia" conoce el límite de la "justicia” que debe pautar la acción del comisario. Forastero en Sucupira, Zeca Diabo otorga valor a lo que la cotidianeidad entorpeció y pone en movimiento una dimensión de la estructura institucional que hasta entonces parecía que dormitaba. No sorprende que esta resistencia exaspere al coronel, que desea implementar su proyecto a cualquier costo: "ODORICO: Y además, capitán yo no estoy necesitado de un doctor en leyes. Necesito un hombre decidido, de poca charla, un hombre de acción” factocto mentadoán")er costo: (za evistaaducidas por el traductor. Nota del editorr sus rencias. e podonsumo de los 30 que uste(p. 123). La existencia del límite legal se ve como un estorbo sin sentido, como un obstáculo inaceptable al desarrollo propuesto, descalificando a aquellos que a él se ciñen. "ODORICO: ¿Sabe lo que yo creo? ¿Que usted se volvió un holgazán” (p. 123).

Obsesionado por la implementación de un proyecto cuyo sustento político se ha fragmentado, Odorico comete el pecado mortal de explicitar la realidad antagónica fundamental que la costumbre silencia. Al creer que su poder de facto (fundado en el reconocimiento social que le otorga su condición económica) puede contraponerse abiertamente al requisito de validación legal, Odorico subestima la profunda relevancia de las instituciones en tanto que valor social.

La explicitación de ese antagonismo (poder de facto/ley), y la intención de no considerar abiertamente los límites que las diferentes instituciones representan, precipita la deslegitimación de Odorico, incluso dentro de su propio grupo social. El pacto que los unía como clase era el de utilizar el aparato institucional en beneficio propio, como herramienta de validación de un sistema jerárquico resultante de otro orden previo. Destruir el sistema imposibilita aquella validación esencial y desemboca en un mecanismo primordial para arbitrar las eventuales diferencias de poder internas en el grupo. Al atacar las instituciones, Odorico genera, inesperadamente, un consenso de tipo inverso de aquel con que se empezó la trama, es decir, hay algo que limita el poder del coronel: la ley.

Este nuevo consenso alinea en el mismo campo, aunque provisoriamente, a las hermanas Cajazeiras (quienes quieren enterrar la hermana fuera de Sucupira, en respeto a la voluntad expresada en testamento por el padre), a Zeca Diabo y al pueblo. Desnudado en su lógica autoritaria, el discurso de Odorico, antes eficaz, surge como impostura y se transforma en indicador de su desvarío: "ODORICO: ¡Es el Derecho, es la Libertad, es la Civilización cristiana las que están en juego! O enterramos a Doña Dulcinéa, ¡o nos enterramos a nosotros mismos!" (p. 103).

La risa que nos provoca el argumento desesperado surge de la referencia a la protección al Derecho y a la libertad como forma de sustentar, justamente, a quien de modo sistemático desconsideró lo judicial como un locus de poder. Es la intervención de la ley la que protege a Neco y la que ratifica a las Cajazeiras la que, a su vez, desautoriza a Odorico. Será una decisión judicial, pues, la que frustre su intento de implementar, contra todo y todos, un proyecto ahora percibido como farsa:

ZECA: ¿¿Señor alcalde? ODORICO: ¿Qué quieren? Ustedes...

ZECA: Aquí traigo una orden. (Muestra un papel.)

ODORICO: ¿De quién? 
ZECA: Del juez.

VICARIO: ¿ No le dije?

ODORICO: Usted recibe órdenes mías, no del juez.

ZECA: No es así.

ODORICO: ¿¿No?

ZECA: Hablé con el juez y él me lo explicó: esta orden anula la suya. Es la ley.

$[\ldots]$

ODORICO: Pues si esa es la decisión de la Justicia, digan al reverendísimo juez que no la acepto.

JUJU: ¡Pero es el juez!

HILÁRIO: ¡Usted no puede recusarse para cumplir una decisión de la Justicia!

ODORICO: También tengo jurisprudencia firmada sobre el asunto. ¡El difunto es mío y nadie me lo quita!

HILÁRIO: Comisario, la Policía tiene que garantizar el cumplimiento de la orden judicial.

ZECA: Déjelo conmigo.

ODORICO: ¿Quién lo garantizará?

ZECA: Yo mismo.

ODORICO: ¿Y quién es usted?

ZECA: ¡El comisario! ¡Santo cielo!

ODORICO: (Agarra un papel sobre la mesa) Lo destituyo (espera una reacción violenta de Zeca Diabo.)

ZECA: (Muy ofendido, su reacción es infantil, como la de niño al que le quitaron su juguete.) Destituido... pero yo no hice nada... yo sólo quería cumplir la ley... mi Padim Pade Ciço ${ }^{18}$ es testigo... ¿ ¿Su merced no está satisfecho conmigo?

ODORICO: Con usted, bastante; no estoy satisfecho es con la ley (p. 112).

\section{4. “Siempre sospeché de ese juez”. Lecturas del desarrollo, lecturas de lo Judicial}

La insatisfacción de Odorico con la ley, hay que mencionarlo, sale a la luz apenas en el momento en que esta surge como obstáculo o límite objetivo a la implementación de sus proyectos. La existencia de las instituciones jurídicas permanece invisible hasta este punto de la trama, pues funcionaban al unísono con el poder de facto del coronel. La presencia organizadora del Derecho - que garantiza, por ejemplo, el acceso al puesto de alcalde y la posibilidad de nombrar y destituir funcionarios- y su funcionamiento en la reglamentación de intercambios sociales pasan desapercibidos, cuando actúan como instrumento de validación de formas jerárquicas de control social. Pero esto no implica, como erróneamente supone Odorico y como deja claro el desenlace de la comedia, que la legitimidad del Derecho "resulte" de esa validación del status quo, o que su autoridad suponga la aprobación de otras esferas del poder constituido.

Aunque en el día a día de Sucupira, la frecuencia con la que se mezclan las fronteras de los campos del poder jurídico y del poder económico amenace generar la impresión de que el primero no es sino "instrumento" para la consecución del segundo, el hecho es que ambos no son intercambiables, sino que se validan en base a fundamentos divergentes e implementan dinámicas de intervención a veces antitéticas. Las decisiones del juez, le guste o no a Odorico, existen a "despecho" y "más alla’" del poder del coronel.

Ese descubrimiento de que las instituciones jurídicas se organizan, funcionan y se validan según una lógica propia, irreductible a las voluntades de la política episódica y a los dictámenes puntuales de la doctrina económica vigente, genera una crisis en el espacio del poder y determina el surgimiento de una lectura que presenta a los jueces y al poder judicial como piedras resbalosas, elementos de atraso y enemigos del desarrollo:

\footnotetext{
${ }^{18}$ En referencia Cícero Romão Baptista, padre católico, muy influyente en el nororiente de Brasil.
} 
ODORICO: ¿Habló con ellos?

VICARIO: Pasé toda la noche intentando convencerlos.

ODORICO: ¿¿Lo logró?

VICARIO: No. Hicieron hincapié en llevar el cadáver a Juaguatirica.

ODORICO: Sólo si llevan también el mío.

VICARIO: Desafortunadamente, ellos tienen los medios para obligarnos a ceder. ODORICO: ¿Qué medios?

VICARIO: Las Cajazeira requirieron al juez un permiso para llevar el cuerpo.

ODORICO: El juez es persona de bien, justo, honesto, honrado, cristiano, no lo otorgará...

VICARIO: Ya lo otorgó.

ODORICO: Juez canalla. ¡Sinvergüenza! Siempre sospeché de ese juez (Dias, 2010, p. 168).

La evaluación del magistrado como "justo" o "canalla", se ve con claridad, no resulta de la calidad jurídica de su sentencia, de la corrección procesal de los procedimientos, ni de su honestidad personal; es fruto únicamente de su utilidad relativa para los proyectos del alcalde. El juez "honesto" es el que actúa como instrumento eficaz en la implementación de las políticas del coronel, mientras que "sinvergüenza" es el juez que impone límites a su acción. La frustración de la expectativa lograda y su sorpresa al encontrar un locus de resistencia dónde buscaba una instancia de validación hacen que Odorico pase a cuestionar, significativamente, no tanto las premisas de su proyecto, sino más bien la integridad del poder judicial ("siempre sospeché de ese juez").

Las furiosas diatribas de Odorico en contra de las instituciones jurídicas que no logra controlar, sugieren un modo de leer el Derecho que estriba, con mayor o menor evidencia, en las premisas implícitas en el discurso de Galbraith. En ambos casos, la divergencia es desautorizada como irrelevante o sin sentido ${ }^{19}$ pues, si las elecciones están previamente dadas ("no existe una gran diferencia entre lo que conservadores, liberales o socialdemócratas serán forzados en hacer"), hay poco espacio para que se entienda el poder judicial como instancia que garantiza la expresión de la divergencia política (que cuestiona precisamente la idea de falta de elección), o como instrumento de la estructuración de lo "contradictorio", en un sentido amplio. Como observa Bauman, esta mirada instaura "un axioma del discurso público que todo lo que económicamente 'tiene sentido' no necesita del apoyo de ningún otro sentido - político, social o categóricamente humano" (1967, p. 61).

En otros términos: los discursos chocan (y los jueces se vuelven "canallas") porque la premisa de un camino único para el desarrollo económico tiene como corolario necesario la garantía de "previsibilidad" de los comportamientos posibles dentro del cuerpo social. Sin ella, se hace imposible planear y ejecutar políticas que tengan como fundamento para su suceso la correcta evaluación de riesgos y oportunidades futuras. Según esa perspectiva, la función del Derecho es contribuir para la construcción de ese marco de certidumbre que es prerrequisito para la acción económica, al impedir que se multipliquen las variables a considerar.

Ejemplo paradigmático de esa mirada sobre lo Judicial es el documento "What Governments Can Do To Facilitate the Enforcement of Contracts" preparado por Richard E. Messick para el Banco Mundial en 2005:

\footnotetext{
${ }^{19}$ De ahí el hecho de que, no obstante el júbilo con el que son celebradas entre nosotros (como símbolo de nuestra pertenencia al rol de las grandes naciones democráticas) las instituciones brasileñas, en la práctica y repetidas veces, se vean cuestionadas cuando dan voz al disenso político o cuando se contraponen a proyectos gubernamentales, como tristemente ilustran las purgas y casaciones del período militar; o la impaciencia con el Legislativo y con el Judicial que, a menudo, emergen en el discurso de quienes ocupan el Ejecutivo.
} 
Los tribunales son la institución más importante en la aplicación de los contratos. No sólo porque son el último recurso en caso de incumplimiento sino también porque la amenaza de una acción legal puede impedir dicho incumplimiento. Las etapas procesales deberían ser simplificadas y las gestiones y el procesamiento automatizados. Se debería examinar la existencia de incentivos para que los abogados algunas veces retrasasen el seguimiento de los procesos; en caso de que dichos incentivos existan, deben ocurrir cambios en el modo en que la profesión está reglamentada para que dichos incentivos sean removidos. Aunque la reforma de los tribunales sea, en última instancia, responsabilidad del poder judicial el Ejecutivo puede tomar la iniciativa al garantizar que el uso de las vías judiciales sea eficiente y consistente con el interés público más amplio (2005, p. 3; énfasis del autor $)^{20}$.

La importancia institucional de los tribunales es típicamente reconocida en conexión con su potencial para establecer un ambiente de certidumbre para el cumplimiento de los contractos, base jurídica de la acción económica. De manera significativa, se recomienda que el espacio de lo contradictorio sea regulado ("las etapas procesuales deberían ser simplificadas"), y su tiempo abreviado ("gestiones y procesamiento automatizados"; "ocurrir cambios en el modo en que la profesión está reglamentada para que dichos incentivos [para atrasar el seguimiento de los procesos] sean removidos") con el objetivo de generar resultados tan rápidos y predecibles como sea posible. En ese proceso, se insinúa una configuración particular de relación entre los poderes del Estado. El Ejecutivo debe hacer "uso" de los tribunales de manera "eficiente y consistente con el interés público más amplio". El documento no desmenuza, aunque quizás Odorico pudiera aclararlo, lo que sería "uso eficiente y consistente", ni en qué debe basarse el Ejecutivo para definir lo que es "interés público más amplio", pero aparecen claramente tanto la obsesión con la previsibilidad como la sospecha de que cierto tipo de funcionamiento de las instituciones judiciales pueda representar un obstáculo al bien común.

El diagnóstico peculiar sobre las trabas a la reforma de lo Judicial, que surge al final del documento, parece resultar del mismo orden de preocupaciones: "Un desafío especial en la reforma de los tribunales es que el Judicial es, generalmente, un poder independiente y separado. El Ejecutivo puede presionar los jueces hacia una reforma y lo Legislativo puede aprobar leyes que dinamicen procedimientos, pero la implementación depende de los tribunales" (p. 14; énfasis del autor). La condición de poder independiente de la cual se reviste el poder judicial es vista como "desafío a superar", como problema a resolverse, como obstáculo que puede frustrar tanto la insistencia del Ejecutivo como la cooperación del Legislativo. "Si esa es la decisión de la Justicia”, diría Odorico, "digan al reverendísimo juez que no la acepto".

La oposición entre los campos, que esa perspectiva insinúa, se desdobla habitualmente en la solicitud de cambios (reformas, modernización) en las instituciones jurídicas para que sean más eficientes en garantizar aquella previsibilidad que el planeamiento económico requiere. Esa lógica puede ilustrarse, una vez más, con los documentos del Banco Mundial: los indicadores que componen el ítem Contract Enforcement del influyente informe anual Doing Business recompensan con puntos positivos las reformas del sistema jurídico que reduzcan el número de etapas en el proceso, el tiempo y el costo de la justicia, ya que "en la ausencia de tribunales eficientes, las empresas emprenden menos inversiones o transacciones comerciales" (World Bakn,

\footnotetext{
20 "Courts are the most important public contract enforcement institution. Not only because they are an avenue of last resort in the event of a breach but because the threat of a lawsuit can deter breach. Court procedures should be simplified and the management and processing of cases automated. The incentives lawyers sometimes have to delay cases should be examined, and where they exist, changes should be made in the way the profession is regulated to remove such incentives. Although court reform ultimately rests with the judiciary, the executive can take the lead by ensuring that its use of the courts is efficient and consistent with the broader public interest".
} 
2008, p. 49) ${ }^{21}$. La misma lógica representa igualmente, con variaciones de énfasis y perspectiva, una parte importante del debate en campos académicos, hoy largamente explorados (como Derecho y Economía) y surge también, con diferentes matices, en la Enmienda Constitucional 45/2004, que trata la reforma del poder judicial.

Ese discurso que defiende instituciones jurídicas más "eficientes" pone en riesgo debido a la fuerza de la propuesta que explicita (¿quién podrá estar en contra de una justicia eficiente?) — la apelación de "consenso" que está en su base. Este discurso busca realizar, en la práctica, el desdoblamiento lógico de la premisa de "falta de elección", que es la afirmación de un camino incontrovertible, en el campo de la política económica, y de un escenario de previsibilidad, en el campo de las relaciones privadas. La eficiencia de las instituciones judiciales, según este punto de vista, estaría en disminuir al máximo los obstáculos, tanto en la implementación de las políticas propuestas (cuyo acierto técnico está objetivamente comprobado) como en la libertad de la actividad económica (cuya piedra de toque es el respeto a los contratos). Al "orden económico" así le correspondería un "orden jurídico" convergente, en el cual Zeca Diabo no necesitaría elegir entre obedecer a Odorico o al juez.

Esa forma de proponer la convergencia entre los dos órdenes (jurídico y económico) amenaza con dejar fuera el espacio de disenso, que caracteriza a los regímenes democráticos y que genera, siempre e inevitablemente, una cierta imprevisibilidad, fruto de la pluralidad de valores en permanente conflicto entre los diferentes grupos sociales. Amenaza también con hacer caso omiso de los males del poder judicial, metiendo en el mismo saco a la morosidad que resulta de la indefendible ineptitud burocrática y al curso cuidadoso que viene del inalienable derecho a la contradicción. No diferencia, pues, la incertidumbre devastadora que resulta de la ausencia de un sistema jurídico democráticamente transparente, y la incertidumbre indispensable de decisiones que responden con justicia a las idiosincrasias de los casos concretos ${ }^{22}$.

Curiosamente, el "desorden" que se instala al inicio de O Bem Amado tiene por base la formación de un "consenso" en torno a un modelo específico de progreso. Lo cómico y mordaz del proceso de transformación del proyecto del cementerio, como solución para la miseria general, y el entusiasmo con que lo abrazan grupos sociales fuertemente antagónicos remiten a la idea de "consenso de base técnica" que se mencionó líneas atrás. Las implementaciones prácticas de este tipo de perspectiva han tenido como corolario frecuente la descalificación de la diferencia política, el intento de silenciar la oposición y la desautorización de modelos divergentes. Más allá de eso, avaladas por indicadores y presentados como "neutros" o "apolíticos", estas también preconizaron un rol específico (y problemático) para las instituciones — sobre todo las del poder judicial—. Según esta mirada, la función de la ley es la de garantizar $-y$ no trabar- la ejecución del modelo consensual de desarrollo.

En Brasil, sobre todo a partir de la década de 1980, ese movimiento tuvo fraccionamientos importantes tanto en el debate político como en la forma de pensar las instituciones. En el ámbito del Derecho, solicitudes más o menos amplias de reforma del poder judicial y propuestas más o menos abiertas de alteración del campo de discrecionalidad de los jueces, ocuparon el lugar central en los diversos proyectos de reformas "estructurales" y de reconfiguración del "ambiente institucional" que se desarrollaron, como algo monótono, desde hace ya algún tiempo.

Esa perspectiva opera para hacer menos visible el papel del Derecho como espacio que garantiza el conflicto y la diferencia, que están en el centro de la perspectiva democrática. Presenta, de igual manera, como ineficientes y defectuosos ciertos modelos de funcionamiento que, vistos de otro ángulo, pueden actuar para asegurar las bases que de manera productiva

\footnotetext{
21 "In the absence of efficient courts, firms undertake fewer investments or business transactions".

${ }^{22}$ En este sentido, recomiendo ver el texto de Adam Prerwoski (1984), "Ama a incerteza e serás democrático".
} 
permiten construir convergencias. La aparente oposición entre el "doctor en leyes" y el "hombre de acción" sólo se sustenta como una simplificación burda de los dos términos, una vez que la garantía institucional de la divergencia actúa, en última instancia, para perfeccionar las formas de pensar, valorar e implementar el desarrollo.

La ambigüedad de las instituciones, sobre todo en el campo jurídico, unas veces acusadas de validación sumisa a intereses de grupos y otras veces de partisan de reivindicaciones legítimas, apunta, justamente a la amplitud de sus oscilaciones; al papel central que estas representan en las formas de significar y organizar la experiencia colectiva en las sociedades democráticas.

\section{Referencias bibliográficas}

Bauman, Z (1997). O mal-estar da pós-modernidade. Rio de Janeiro: Jorge Zahar Editor Bresser-Pereira, L. C. (1991). Washington Consensus or Fiscal Crisis Approach? Working Paper, 6, 1-31.

Castels, M. (1999). A Sociedade em Rede. São Paulo: Paz \& Terra.

Cardoso, F. H. (1995). Pronunciamento de compromisso constitucional perante o Congresso Nacional. <http://www.biblioteca.presidencia.gov.br/ex-presidentes/fernandohenrique-cardoso/discursos-de-posse>.

Da Silva, L. (2008). Discurso na Sessão de Posse, no Congresso Nacional. En L. Da Silva. Discursos Selecionados do Presidente Luiz Inácio Lula da Silva (pp. 7-18). Brasilia: Ministério das Relaçóes Exteriores.

Dias, J. S. (2010). Odorico Paraguaçu: O Bem Amado de Dias Gomes. São Paulo: Imprensa Oficial de São Paulo.

Faoro, R. (2001). Os Donos do Poder: Formação do Patronato Politico Brasileiro. Sao Paulo: Globo. Fukuyama, F. (1998). The End of History? En G. Toal, S. Dalby y P. Routledge (eds.). The Geopolitics Reader (pp. 114-125). New York: Routledge.

Furtado, C. (2007). Formação econômica do Brasil. Sáo Paulo: Companhia das Letras.

Galbraith, J. K. (1986). A Era da Incerteza. 8a Ed. São Paulo: Pioneira.

Garcez Ghirardi, J. (2012). Os "entretanto" do progresso: Representaçóes do desenvolvimento no Brasil e o lugar do Direito. En M. L. Lima (org.). Direito e Economia: 30 anos de Brasil (pp. 402-428). São Paulo: Saraiva.

Habermas, J. (2001). O conceito de poder de Hannah Arendt. En B. Freitag y S. P. Rouanet (orgs.). Habermas (pp. 100-118). São Paulo: Ática.

Lyotard, J. F. (2004). A Condição Pós-Moderna. Rio de Janeiro: José Olympio.

Messick, R. E. (2005). What Governments Can Do To Facilitate the Enforcement of Contracts. En R. E. Messick. World Bank's Online Resources (pp 1-16). <http://siteresources. worldbank.org/INTLAWJUSTINST/Resources/ContractEnforcementCairo.pdf>

Prado, C. (2011). Formação do Brasil contemporâneo. São Paulo: Companhia das Letras.

Prerwoski, A. (1984). Ama a incerteza e serás democrático. Revista Novos Estudos, 9, 36-46.

Przeworski, A., Cheibub, J. A. y Limongi F. (2000). Democracy and Development. Political Institutions and Well-being in the World, 1950-1990. Cambridge, UK: Cambridge University Press.

Schwarz, R. (1992). Ao Vencedor as batatas. São Paulo: Duas Cidades.

World Bank (2008). Doing Business 2009. Washington D.C.: The World Bank. 